\title{
PENSAMIENTO EDUCATIVO DE MENÉNDEZ PELAYO
}

\section{The educational thought of Menéndez Pelayo}

Serafín M. TABERnERo DEL Río

Universidad de Salamanca. Dpto. T. ${ }^{a}$ e Historia de la Educación

Correo-e: insesma@yahoo.es

Recepción: II de diciembre de 2014

Envío a informantes: 20 de enero de 2015

Aceptación definitiva: 3 de marzo de 2015

Biblid. [0214-3402 (2015) (II época) n. ${ }^{\circ}$ 2I; I49-163]

Resumen: En este trabajo se exponen algunos de los problemas educativos españoles tratados por Menéndez Pelayo: consistencia de los mismos, remedios de las deficiencias y propuestas para el futuro, en armonía con los países más avanzados.

Palabras clave: Menéndez Pelayo; deficiencias educativas; reforma universitaria; progreso material.

АвтRAст: This work shows some subjects about Spanish education that were studied by Menéndez Pelayo: theirs determination, remedy of the deficiencies and proposals for the future, in harmony with the much progressives countries.

KeY WORds: Menéndez Pelayo; education; deficiency; University; progress.

0 e pretende, en este trabajo, exponer parte de lo que Menéndez Pelayo pensó y escribió sobre la situación cultural y educativa de la España de su tiempo. Y ello es debido a que, a nuestro juicio, muchas de sus ideas son actualmente sumamente aprovechables. De acuerdo con ese fin, se procederá según los siguientes apartados: I- Introducción: Precocidad de Menéndez Pelayo y Polémica de la ciencia española. II- Decadencia educativa y cultural de España: El olvido de la propia historia. La Universidad reformada como remedio. Conclusiones. 


\section{Introducción}

\section{I.I. Precocidad de Menéndez Pelayo}

Es este uno de los temas más traídos y llevados por cuantos se han ocupado de la figura y de la obra de nuestro sabio. Para comprobar su veracidad, basta con traer a colación la edad en que publica algunos de sus trabajos. Recuérdese que D. Marcelino Menéndez Pelayo nace en i856. Pues bien, he aquí, entre paréntesis, los años en que ven la luz algunas de sus obras: Estudios críticos sobre escritores montañeses. Trueba y Cosío (1876); Polémicas, indicaciones y proyectos sobre la ciencia española (1876), obra ésa que aparecerá, en I880, con no pocas correcciones y con el título La ciencia española, tres volúmenes; Historia de los heterodoxos españoles: tres volúmenes, aparecidos los dos primeros en I880 y el tercero en I882; Calderón y su teatro (I88I).

Añádase a lo dicho, y como consecuencia de ello, que gana, con sólo veintiún años, la cátedra de «Historia Crítica de la Literatura Española»; y en I88I, esto es, a los veinticinco años, ingresa, como académico numerario, en la Real de la Lengua. Pocos años después, lo sería también de la Real de la Historia, de la de Ciencias Morales y Políticas y de la de Bellas Artes.

Los referidos y otros hechos hicieron que se disparase la imaginación de la gente no demasiado ilustrada y convirtiera a D. Marcelino en un auténtico mito. Así lo manifiestan las siguientes palabras de D. Miguel Artigas y D. Enrique Sánchez Reyes, en la Advertencia de la edición de la Historia de los heterodoxos españoles de 1946, páginas XII y XIII:

... comenzó el tejido de leyendas fabulosas, como las de los héroes de la antigüedad, y el hacerse todo el mundo lenguas de su saber: él leía dos páginas a un tiempo, una con cada ojo, retenía fielmente libros enteros y decía de memoria el lugar en que se hallaban las cuestiones en ellos tratadas, sabía el lugar y signaturas de cualquier volumen de la Biblioteca Nacional y no había conocimiento humano sobre el que no pudiera sentar cátedra.... ${ }^{\mathrm{N}}$.

Estas disparatadas afirmaciones no solo no halagaban a D. Marcelino, sino que le molestaban enormemente, ya que parecían indicarle que sus trabajos eran resultado de su prodigiosa memoria y no de su capacidad de trabajar, constante y disciplinadamente, con arreglo a los más modernos métodos de investigación histórica. Pero, dentro de la sensatez, no han sido pocos los elogios sobre el gran maestro emitidos por las cabezas más relevantes del mundo ilustrado: de Cajal, Marañón, Bonilla y San Martín, Araquistain..., entre los coetáneos del gran santanderino; y, entre los posteriores, incluso actuales, son de destacar los elogios de Sainz Rodríguez, Laín Entralgo, Alonso de los Ríos, Juan Goytisolo...

He aquí el modo como D. Gregorio Marañón comparaba la precocidad de D. Marcelino con la tardía madurez en la que el gran benedictino Feijoo inició la publicación de su, por lo demás, también grandiosa producción:

... Menéndez y Pelayo no fue un hombre de talento, sino un genio. Lo sabía todo como por arte de ciencia infusa, en plena juventud. Si Feijóo puede compararse a Don

I Menéndez Pelayo, Marcelino (1946) Historia de los Heterodoxos Españoles. Madrid: csic, p. XIIs. Respeto los números romanos que indican las páginas de la advertencia citada. 
Quijote, que se decide a derribar gigantes, después de medio siglo de meditación sobre sus libros de caballería, Menéndez y Pelayo se podría comparar con David, que desde niño derribaba a los gigantes por la gracia de Dios $^{2}$.

Y, páginas más adelante, se refiere así a las célebres oposiciones a cátedras que, como queda ya dicho, Menéndez Pelayo realizó y aprobó, a los veintiún años:

La ciencia del juvenil opositor fue tal, que las intrigas políticas, los intereses inconfesables y los méritos indiscutibles de los otros opositores fueron arrollados como por un huracán, que no otra cosa parecía el torrente inacabable de erudición y de crítica genial que brotó de los labios de Menéndez y Pelayo, ante el asombro del público y de los jueces. Don Juan Valera, que formaba parte del tribunal, solía contar, años después, y yo se lo oí, la estupefacción de los jueces... ${ }^{3}$.

Las «intrigas políticas» a las que Marañón se refiere son las surgidas como consecuencia de que, para que Menéndez Pelayo pudiera opositar con sólo veintiún años, el Gobierno hubo de rebajar la edad reglamentaria que era de veinticinco, lo cual hizo apoyándose en los consabidos méritos del joven sabio.

Expongamos, ahora, cómo enjuicia al Menéndez Pelayo de la madurez D. Luis Araquistain (1886-1959), en su libro Elpensamiento español contemporáneo. Recuérdese que Araquistain perteneció a la izquierda más radical del partido socialista, y que, entre otros países, fue embajador de España en Francia, durante la Segunda República. Pues bien, en dicha obra, sale al paso del falaz aprovechamiento de Menéndez Pelayo como soporte intelectual por parte del franquismo. Las siguientes son sus palabras:

Me he detenido, quizás excesivamente, en el examen del pensamiento y la figura de este español excepcional, no sólo por tratarse de uno de los valores culturales más eminentes que ha producido España en toda su historia y uno de los que más han influido en el renacimiento científico contemporáneo, sino también porque ahora se está usando y abusando de su nombre como uno de los sostenes intelectuales del régimen ignominioso que allí [en España] impera. Nada más extraño a él [a Menéndez Pelayo] que ese régiment.

Y, una página más adelante, insiste:

El Menéndez Pelayo... que se proclamaba a cada paso «pensador independiente y ciudadano libre en la república de las letras» [...] no pertenece ni puede pertenecer a la España de Franco, del mismo modo que esa España tampoco pertenece ni puede pertenecer a la república de las letras de Menéndez Pelayo, que es también la nuestra. Gran humanista y en el fondo profundamente sensible y humano, hubiera aborrecido, como nosotros, a los que en la trágica España de hoy han hecho «del brutal ejercicio de la fuerza»..., su única razón de sers.

Los testimonios expuestos sobre Menéndez Pelayo revelan que éste fue y es sumamente valorado por los más destacados representantes de la cultura, cualquiera que sea el credo político en que cada cual se alineara o alinee. Y revelan, también, que sólo

Marañón, Gregorio (1960) Tiempo viejo y tiempo nuevo. Madrid: Espasa-Calpe, p. 84s.

Marañón, G.: Ibidem, p. 93.

Araquistain, Luis (19682) El pensamiento español contemporáneo. Buenos Aires: E. Losada, p. 54. ARAQUISTAIN, Luis: Ibidem, p. 55 . 
la ignorancia justifica que, en ciertos sectores de la clase media intelectual, se quiera actualmente hacer caso omiso del gran santanderino.

\section{I.2. Ante la polémica de la ciencia española}

El salto juvenil de Menéndez Pelayo a la palestra publicitaria estuvo motivado por esa polémica sobre la cual se pueden sintéticamente citar tres grupos: . $^{\circ}$ ) el formado por autores pertenecientes o afines al krausismo o al positivismo, los cuales afirmaban, según expresión de D. Manuel de la Revilla, que «en la historia científica no somos nada», y ello como consecuencia de la coartación de la inteligencia por parte de la Inquisición; $2^{\circ}$ ) el radicalmente opuesto al anterior, integrado por autores defensores del pensamiento medieval, para los que el pensamiento moderno, por ser un inmenso y radical error, no merece la más mínima atención; y, por tanto, carece de importancia o es un mérito que España no participe o haya participado en él; y $3 .^{\circ}$ ) el formado por quienes sí concedían importancia a las conquistas científico-culturales de la modernidad -las realizadas a partir del s. Xv- y creían que España había participado en ellas y que, sin olvidarlo, debería recobrar esa línea de trabajo.

Resulta claro, por lo ya dicho, que Menéndez Pelayo se incorporó al tercero de los grupos, y que, para defender su postura, escribió su citada obra La ciencia española. Admite, sí, la postración intelectual en que, en el tiempo en que escribe, se encontraba España; pero no debido a herencias inquisitoriales, sino a la negación u olvido de nuestro pasado. Veámoslo.

\section{La decadencia educativa y cultural de España: causas y remedio}

\section{I. El olvido español de la propia historia}

Juzgaba D. Marcelino que, a lo largo del siglo xix, se había ido promoviendo el olvido de nuestro pasado y su sustitución por foráneos modos de pensamiento: así lo manifiesta en varios pasajes de la Historia de los heterodoxos... Juzgaba también que tal desprecio u olvido era la causa del bajón educativo-cultural de España, causa y efecto que seguían actuando y produciéndose, en la primera década del siglo xx. Así lo expresó en riıro, dos años antes de su muerte, en su discurso Dos palabras sobre el centenario de Balmes, pronunciado para conmemorar los cien años del nacimiento del filósofo de Vich:

... Hoy presenciamos el lento suicidio de un pueblo que, engañado mil veces por gárrulos sofistas, empobrecido, mermado y desolado, emplea en destrozarse las pocas fuerzas que le restan, $\mathrm{y}$, corriendo tras vanos trampantojos de una falsa y postiza cultura, en vez de cultivar su espíritu propio..., hace espantosa liquidación de su pasado, escarnece a cada momento las sombras de sus progenitores, huye de todo contacto con su pensamiento, reniega de cuanto en la historia lo hizo grande ¡De cuán distinta manera han procedido los pueblos que tienen conciencia de su misión secular!

6 Menéndez Pelayo, M. (mсmxiviiI) Ensayos de Crítica Filosófica. Madrid: csic, p. 354. 
Y, a renglón seguido de estas palabras, cita a Alemania e Italia, como ejemplos de países que han sabido cimentar su actual grandeza intelectual sobre sus respectivas tradiciones. E insiste:

... Donde no se conserva piadosamente la herencia de lo pasado..., no esperemos que brote un pensamiento original ni una idea dominadora. Un pueblo nuevo puede improvisarlo todo menos la cultura intelectual. Un pueblo viejo no puede renunciar a la suya sin extinguir la parte más noble de su vida y caer en una segunda infancia muy próxima a la imbecilidad senil?

\subsection{La Universidad como remedio}

Le acuciaba a D. Marcelino remediar la susodicha lastimosa situación cultural, educativa, en que España se encontraba sumida. Y creyó que, para remediarla, era preciso rehabilitar primero la Universidad, para que luego ésta dirigiera la rehabilitación educativa y cultural de todo el país: por ello, consideró necesario comenzar el cambio por esa institución, ya que ésta se encontraba tan lejos de lo que debía ser como todas, o casi todas, las instituciones restantes. Pero ¿cómo lograr esa primera rehabilitación? Veámoslo en los siguientes apartados:

- Contenido de la enseñanza y caracteres de la Universidad.

- Los alumnos: su acceso y permanencia en la institución universitaria.

- El profesorado: carrera docente.

Fiel a su convencimiento del maléfico olvido de la propia historia, Menéndez Pelayo propone la recuperación de nuestra tradición científica para seguir progresando, y, con tal propósito, escribe en La ciencia española (1876):

La enseñanza en España apenas tiene de española en el día más que el nombre; está casi todo desligado de nuestra tradición científica, y los esfuerzos de algunos sabios profesores no bastan para infundirle el carácter nacional de que mucho ha la despojaron las torpezas oficiales...8.

A continuación de estas palabras, nos dice el sabio polígrafo, en la misma página, que los libros de texto que circulaban por las aulas cuando él escribía, en I876, eran extranjeros, así como también los autores y doctrinas de que en ellos se hablaba. Y sobre la en su opinión causa de tal hecho escribe:

... Ha reinado aquí una insensata manía de remedar fuera de propósito todo lo que ultrapuertos estaba en boga, y, sin pararnos en barras, importamos (siempre tarde, mal y a medias) teorías, libros, planes de enseñanza, programas, todo a medio mascar y sin cuidarnos de si encerraba o no elementos discordantes...

Y señala, inmediatamente a continuación de las anteriores palabras, las consecuencias de dicho remedo:

8 Menéndez Pelayo, M. (I876) La ciencia española. Madrid: csic, I953, p. I72s. 
... Así nuestro actual sistema de estudios es un mosaico, en que hay todo y para todos los gustos, menos para el gusto español puro y castizo. En nuestras cátedras se puede aprender la historia de la filosofía india o china, pero no la de la filosofía española...?.

Se queja después, D. Marcelino, de que, en los años de referencia, se podía salir de las Facultades de Letras sin haber oído jamás una palabra sobre Vives o Fox Morcillo, o sobre Séneca, Marcial o Lucano. Y manifiesta que hasta la Literatura carecía de la debida presencia en esas Facultades, pues sólo había en ellas un apéndice «agregado a la literatura general en un solo curso», y una única cátedra en el doctorado que, además, había estado suprimida durante varios años.

Ante tales hechos, formula nuestro autor el siguiente interrogante, en las mismas páginas de las palabras últimamente citadas:

... ¿No sobra motivo para afirmar que si tal estado de cosas continúa ha de llegar día en que reneguemos hasta de nuestra lengua y de nuestra raza y acabemos de convertirnos en un pueblo de babilónicos pedantes, sin vigor ni aliento para ninguna empresa generosa, maldiciendo siempre de nuestros padres, y sin hacer nada de provecho jamás?

Al llegar aquí, se hace preciso recordar que Menéndez Pelayo no propugnaba la presencia en las aulas de nuestra pasada cultura, para quedarnos detenidos en la pasiva contemplación de la misma o en su mera repetición, sino como punto de arranque para seguir avanzando. Así lo proclamaba en memorable discurso pronunciado en I889:

... Y, al respetar la tradición, al tomarla por punto de partida y arranque, no olvidamos que la ciencia es progresiva por su índole misma y que de esta ley no se exime ninguna ciencia... ${ }^{\mathrm{I}}$.

A continuación, como ejemplo de ese progresivo carácter del saber científico, pone un caso histórico muy concreto: el de las diferentes exigencias discursivas de la polémica religiosa a lo largo de los años. Éstas son sus palabras:

... aunque quisiéramos detenernos sería empeño imposible, porque la impiedad no se detiene y cada día levanta nuevas máquinas de guerra contra la ciudad espiritual en que nacimos. Las exigencias de la polémica religiosa son ya muy otras que en el siglo XVI ${ }^{\text {II }}$.

Ya en el siglo xx, concretamente en I9ıo, reitera D. Marcelino que nuestros planes de estudio "han sido copia servil de la legislación francesa», con la consecuencia de que nuestros males se han ido continuamente agravando. Y, a este respecto, hace mención de tres determinados hechos:

I. $\left.^{\circ}\right)$ El abandono del estudio de las lenguas clásicas.

2. ${ }^{\circ}$ La desaparición de la única cátedra de Historia Eclesiástica que existía entre nosotros.

$\left.3 .^{\circ}\right)$ Y la anterior desaparición de la Facultad de Teología de nuestras Universidades.

9 Menéndez Pelayo, M.: Ibidem, p. I72s.

ro Menéndez Pelayo, M. (i948) Ensayos de Crítica Filosófica (edic. cit.), p. 297.

" Menéndez Pelayo, M.: Ibidem, p. $297 \mathrm{~s}$. 
En relación con el estudio del latín y el griego, escribe en el mismo texto de i9ı:

El cultivo de las leguas sabias, sin el cual no hay erudición sólida, está vergonzosamente abandonado, con pocas y por lo mismo más loables excepciones ${ }^{12}$.

Sobre la desaparición de la cátedra de Historia de la Iglesia comenta que poco se ha perdido con ello, ya que, al ignorar las mencionadas lenguas, nuestros canonistas apenas si podían penetrar en dicha historia.

En cuanto a la eliminación de la Facultad de Teología de nuestras Universidades, el sabio polígrafo considera un oprobio que sea la patria de Suárez y de Melchor Cano el único país europeo que ha llevado a cabo tal eliminación:

Todos, católicos y protestantes -escribe-, la conservan, sin que este acatamiento rendido a la ciencia de las cosas divinas en centros de cultura abiertos a todo el mundo, se considere como signo de atraso en Alemania ni en Inglaterra ni en parte alguna ${ }^{13}$.

Para los creyentes, aparece obvia la importancia del estudio de la Historia Eclesiástica y de la ciencia teológica. Pero, al margen del valor propedéutico para esas disciplinas, ¿existen para las lenguas clásicas, según Menéndez Pelayo, razones que sólidamente sustentan su estudio? La respuesta a este interrogante es de enorme actualidad, y de ella se ocupa el gran polígrafo en diversos lugares de su obra. Y las razones que aduce en pro del estudio del latín se pueden resumir del siguiente modo:

I. $\left.{ }^{a}\right)$ El ser el latín fuente de las lenguas romances y, por tanto, de todas las lenguas peninsulares excepción hecha del vasco.

$\left.2^{a}{ }^{a}\right)$ El ser, entonces, la lengua de la Iglesia.

3. $\left.{ }^{a}\right)$ El haber sido la lengua del Derecho y aun de la cultura universal científica.

En cuanto al estudio del griego, las razones aducidas son:

I. $\left.{ }^{a}\right)$ El poseer una literatura superior a la latina en perfección estilística, originalidad y riqueza conceptual.

2. $\left.{ }^{a}\right)$ El haber sido la lengua del Nuevo Testamento y de los Padres Apostólicos.

3. ${ }^{a}$ « $\ldots$ el que casi todos los tecnicismos científicos están basados en esa lengua incomparable, que tantas facilidades presenta para la composición de palabras y para expresar por este medio las ideas más nuevas y más complejas» ${ }^{14}$.

Y, en 1908, nuestro sabio reconoce, a favor de todas las Humanidades, el valor que tienen para formar caracteres dotados de serenidad, coherencia y armonía. Es ésa una de las razones por las que siempre había querido tomar como punto de partida la cultura tradicional española, para continuar con una línea de progreso acorde con los tiempos. Con ello deseaba hacer de España una nación moderna, con auténtico perfil europeo. En tal sentido, proclama una y otra vez la necesidad de abrirse, en el campo filosófico, a lo ajeno y a lo nuevo. Así, en el prólogo al libro Algazel del

${ }_{12}$ Menéndez Pelayo, M. (I9IO²) Advertencia preliminar. En Historia de los Heterodoxos... Madrid: csic, I, p. I9.

I3 Menéndez Pelayo, M.: Ibidem, p. 20.

${ }_{14}$ Menéndez Pelayo, M. (1953) Bhlc (Bibliografía Hispano Latina Clásica), x, p. I6zs. 
insigne arabista D. Miguel Asín, publicado en ı9o, D. Marcelino copia y comenta las siguientes palabras de dicha obra:

... Así como Alberto Magno, Raimundo Martí, Lulio y otros muchos no se avergonzaron de tomar de la filosofía arábiga todo lo que encontraban de utilidad para adaptarlo a la dogmática cristiana, no de otro modo debemos en nuestros días aprovechar todo legítimo progreso que aparezca en la literatura filosófica contemporánea, seguros de que así hacemos avanzar a la filosofía cristiana más y mejor que permaneciendo petrificados en los textos que ya pasaron, atentos exclusivamente a repetirlos y comentarlos ${ }^{15}$.

Y el siguiente es el breve comentario que de las anteriores palabras de Asín hace D. Marcelino, en la misma página:

Léanse atentamente estas palabras suyas que hago mías, sin restricción ninguna, y que pueden marcar un nuevo rumbo a muchos espíritus pusilámines y asustadizos.

Líneas antes de esas palabras, escribió estas otras como saliendo al paso de esos pusilámines y asustadizos varones:

Para nadie puede ser motivo de escándalo la singular historia de un místico musulmán que viene a través de los siglos suministrando armas a los más sabios defensores del dogma cristiano. Por el contrario, debemos admirar e imitar la tolerancia insigne, el amplio criterio ecléctico con que los maestros de la Escolástica en el siglo XIII incorporaron en el vasto organismo de su ciencia todo lo que había de útil y de eternamente verdadero en la especulación filosófica anterior, tal como ellos la conocieron ${ }^{16}$.

Pero no era sólo esto lo que D. Marcelino quería para la cultura filosófica de su patria, sino además, la restauración de la Metafísica contra la corriente positivista que él creía próxima a declinar. Y esa restauración pensaba que había de hacerse con el sólido apoyo de la ciencia experimental moderna. Percibió y formuló, pues, lo que, con posterioridad de muchos años, Zubiri expresaría como «necesidad de una metafísica intramundana». Tales opiniones fueron expuestas por Menéndez Pelayo en un famoso discurso pronunciado en Palma de Mallorca, allá por I884, en el que llegó a propugnar la instauración de una especie de «hegelianismo cristiano».

Se preocupa también, D. Marcelino, del progreso material de España, según manifestó, al hablar en varias ocasiones de la Facultad de Ciencias. Así, en i894 y en I909, expresó la necesidad de que existiera entre nosotros una auténtica industria que redundara en beneficio de todos los españoles.

Consecuentemente con lo dicho, escribe Laín Entralgo en su importante obra sobre nuestro sabio:

Cristianismo operante quería. En la base de la futura y posible grandeza, una fe religiosa capaz de hablar al mundo el lenguaje inédito, tanto tiempo anhelado de una vida eficaz y verdaderamente cristiana: un lenguaje total y armónico, concertadamente pronunciado por la teología, el pensamiento filosófico, la ciencia, la técnica y la convivencia social. ¿Sonará algún día en el mundo..., esta anhelada, necesaria voz? ${ }^{17}$.

is Menéndez Pelayo, M. (1948) Ensayos de Crítica Filosófica, edic. cit., p. 349.

i6 Menéndez Pelayo, M.: Ibidem, p. 348.

17 Laín Entralgo, Pedro (I952) Menéndez Pelayo. Madrid: Espasa-Calpe, p. 232. 


\subsection{Reforma Universitaria}

Queda dicho que D. Marcelino creía que estaba en la Universidad el remedio de la postración educativa y cultural de España. Y ello requería el establecimiento de determinadas condiciones que sustentasen dicha institución. Así, en su discurso de apertura del año académico I889-I890, expone, a pesar del uso del gramatical presente de indicativo, más que lo que era entonces, lo que debiera ser el contenido de la enseñanza y aprendizaje universitarios: un contenido del que pudiera decirse:

No es, no, la ciencia que aquí se profesa, ciencia estéril, solitaria, encerrada tras el triple muro de la especialidad y llena de soberbia en su aislamiento...; es función humana, generalísima y civilizadora, que a todos llama a su seno y sobre todos difunde sus beneficios...; aquel orbe armónico de todas las disciplinas, que los griegos llamaron enciclopedia, solo en la institución universitaria está representado y sólo desde la Universidad penetra y se difunde en la vida ${ }^{18}$.

Universidad y vida en íntima conexión: tal era el ideal de Menéndez Pelayo, como primera premisa para regenerar la vida española. Veámoslo; pero digamos antes que la mayor parte de las ideas de D. Marcelino, al respecto, se contienen en un escrito elaborado en colaboración con D. Nicolás Salmerón. El escrito fue encargado a los dos por la Universidad madrileña, para después remitirlo al Ministerio, y tiene este título: Dictamen sobre la reforma universitaria. Pasemos sobre él aunque sólo sea una sucinta revista.

\subsection{Autonomía universitaria}

Pensaban, los referidos autores, que la Universidad debiera tener una «prudente y racional autonomía». Pero, ¿cómo concretaban esa idea? Ante todo con la emancipación de la institución del excesivo control estatal al que estaba entonces sometida. Y esto implicaba dar autonomía al cuerpo universitario, dejarlo hablar y escucharlo cuando se tratase de la enseñanza, pues sobre este tema se presupone que la corporación docente es la que puede emitir juicios de mayor solvencia.

¿Pretendían, los autores del Dictamen, volver al antiguo régimen de la institución? No: lo niegan explícitamente. Ni siquiera pretenden lograr, de forma inmediata, una legislación de tipo autonómico.

Pero sí queremos -dicen- aproximarnos a este ideal por todos los caminos posibles y reivindicar para el cuerpo universitario toda aquella libertad de acción que dentro de su peculiar esfera le corresponde; toda aquella majestad y decoro que nuestra misma ley fundamental le otorga, al concederle amplísima representación en el senado nacional' ${ }^{19}$.

Recordemos que ya en la Historia de los heterodoxos... se había mostrado D. Marcelino abierto partidario de la libertad científica de la Universidad. He aquí sus palabras:

18 Menéndez Pelayo, M.: Ensayos de Crítica Filosófica, edic. cit., p. 9.

19 Menéndez Pelayo, M. y Salmerón, N. (1892) Dictamen sobre la Reforma Universitaria [ı19: ввмp (Boletín de la Biblioteca Menéndez Pelayo)], p. 62. 
Nadie más amigo que yo de la independencia orgánica de las Universidades. Nadie más partidario tampoco de la intervención continua y vigilante de la Iglesia en ellas, no de la inspección laica e incompetente de ministros y directores más o menos doctrinarios. La universidad católica, española y libre es mi fórmula ${ }^{20}$.

¿Significarán las anteriores palabras que Menéndez Pelayo quería, sin más, la subordinación completa de la Universidad a la Iglesia Católica? En modo alguno. Al interrogante responderá el propio polígrafo, tres años más tarde del I882 en que escribió lo que acaba de ser citado. Nuestro sabio, en efecto, pronuncia en 1885 un discurso parlamentario, como réplica a otro de D. Emilio Castelar, en el que éste había defendido, en nombre de la libertad de pensamiento y de la libertad de la ciencia, una revuelta estudiantil. Pues bien, el sabio montañés dice en tal ocasión:

Nosotros no queremos la absoluta dominación de la Iglesia en la enseñanza, como no sea para la continua vigilancia sobre el dogma; ni mucho menos admitimos la inspección laica e incompetente de ministros y directores generales para todo lo que no sea la parte política y la parte disciplinaria, allí donde no alcanzan las atribuciones de los rectores. Queremos, sí, la independencia en la parte científica, pero exigimos del catedrático oficial la sincera adhesión a las grandes instituciones del país ${ }^{21}$.

Libertad e independencia científicas quería para la Universidad Menéndez Pelayo; pero en tanto no fueran contra las instituciones del Estado. En este sentido, sus palabras recién citadas ponen dos cosas de manifiesto: una, que D. Marcelino debió de dejarse llevar de la espontaneidad cuando escribió lo de «sincera adhesión», porque la actitud ante tal exigencia no puede ser comprobada y ésta resulta, por tanto, inútil. La otra cosa es que, planteadas la libertad e independencia científicas como el gran polígrafo lo hace, quedan fuera de ellas las disciplinas jurídicas y filosóficas, ya que las grandes instituciones a que se refiere no son otras que la Iglesia y la Monarquía.

\subsubsection{Los estudiantes: acceso y permanencia en la Universidad}

En el mencionado Dictamen, se expresa que los alumnos debieran someterse sólo a dos pruebas o exámenes: uno, para ingresar en la Universidad; y el otro, para la consecución del título de Doctor.

El examen de ingreso había de durar varios días y abarcar varios ejercicios, orales y escritos, en los que

... el candidato dé muestras de poseer todos aquellos conocimientos preliminares que la facultad determine, del mismo modo que lo practican las escuelas especiales...22.

Respecto al examen para el título de Doctor, en el Dictamen se propone lo siguiente:

- La tesis debería ser una investigación propia que aportase algo nuevo «al caudal de la literatura científica».

- El examen y discusión de la tesis se haría durante varios días, en los que había de comprobarse:

20 Menéndez Pelayo, M. (1948) hie (edic. cit.), p. 277.

${ }_{21}$ Menéndez Pelayo, M. Bbmp, enero-marzo (I927), IX, p. is.

22 Menéndez Pelayo, M. y Salmerón, N. (I892) (BBmp, 1919), p. 595. 
- La capacidad del aspirante.

- Los conocimientos por él adquiridos en cada una de las asignaturas de la Facultad.

- El modo y forma por los que coordina dichos conocimientos «en un más general sentido", es decir, en un sistema.

Llegados a este punto, cabe preguntarse: ¿qué pasa con el grado de Licenciado? Sobre esto se dice en el Dictamen... que quizá sólo debiera mantenerse en las Facultades cuyos alumnos tienen dos salidas: una, la práctica profesional; y otra, la enseñanza de la profesión de que se trate. Entre esas facultades se citan las de Derecho, Medicina y Farmacia. Y se añade que

... no puede, por ningún concepto, sostenerse en las Facultades de Ciencias y Letras, en que los estudios del doctorado son necesarios complementos de los de licenciatura.... ${ }^{23}$.

La razón aducida, para la susodicha supresión, era, pues, que, al llegar a la Licenciatura en las Facultades de Ciencias y de Letras, no se habían cursado algunas asignaturas consideradas fundamentales y que estaban en el doctorado: estética, nociones de sánscrito, historia de la filosofía... Y, claro está, no era entonces tolerable que pudiera ser catedrático alguien por completo ayuno de conocimientos de tales materias. Esto parece razonable; pero a cualquiera se le ocurre preguntar: ¿ exigía lo apuntado la supresión del grado de Licenciatura?; ¿no podían haberse trasladado del doctorado a otros cursos las materias mencionadas? La respuesta afirmativa hubiera sido obvia muchos años después; pero entonces existía una dificultad: que las carreras de Ciencias y de Letras constaban sólo de tres cursos más uno de doctorado, lo cual imposibilitaba encajar en los tres cursos de licenciatura todas las materias importantes. La única salida era alargar las carreras, solución ésta que años más tarde se adoptaría.

Aún nos queda referirnos a los «exámenes de prueba de curso», ya que si sólo habían de existir los exámenes de ingreso y de doctorado, aquellos habían de ser suprimidos, según el susodicho Dictamen. Pero ¿qué razones se aducen para proponer dicha supresión? Ninguna. Para responder al interrogante, hemos de remitirnos al individual juicio que Menéndez Pelayo expresa en Esplendor y decadencia de la cultura científica española (1894). Helo aquí:

... exámenes de pruebas de curso, que en la enseñanza superior son un absurdo atentado a la dignidad del magisterio ${ }^{24}$.

Cabe ahora preguntarse si Menéndez Pelayo era partidario de que, una vez ingresado en la Facultad el alumno, éste estudiase por sí solo, sin el más mínimo contacto con los maestros. La respuesta es no, y ello requiere ser aclarado. Lo que D. Marcelino proponía era algo así como lo que posteriormente se ha llamado «evaluación continua»: valoración del alumno, mediante la continua observación, por parte de los maestros, del modo de trabajar de aquél en estrecha colaboración con éstos. Así lo expresaba nuestro sabio, al hablar de la Facultad de Ciencias, con unas palabras que resumen lo que venimos diciendo:

23 Menéndez Pelayo, M. y Salmerón, N.: Ibidem, p. 59 s.

24 Menéndez Pelayo, M. (1953) La C.E. Madrid: csic, II, p. 438. 
Ojalá tuviese menos alumnos todavía -la Facultad de Ciencias- y fuese lo que debía ser, una escuela cerrada de purísima investigación, cuyos umbrales no traspasase nadie cuya vocación científica no hubiera sido aquilatada con rigurosísimas pruebas, y que entrase allí no como huésped de un día, sin afición ni cariño, sino como ciudadano de una república intelectual, a la cual ha de pertenecer de por vida, ganando sus honores en ella, no con risibles pruebas de curso..., sino con la colaboración asidua y directa en los trabajos del laboratorio y de la cátedra.... ${ }^{25}$.

Y añade, a renglón seguido, las condiciones en que debiera desarrollarse tal modo de trabajar:

... como se practica en todas partes del mundo, sin plazo fijo para ninguna enseñanza, sin imposición de programas, con amplios medios de investigación y con la seguridad de encontrar al fin de la jornada la recompensa de tantos afanes...

Para una Facultad de ese estilo, era consciente nuestro autor de que se requerían amplios medios de investigación, y así lo hace constar explícitamente. Y era también consciente que tal Facultad era imprescindible para la regeneración científica de España. Mas ¿cómo convertir en realidad tan ambicioso propósito? Se precisaba, antes que ninguna otra cosa, crear en la sociedad española una actitud favorable a los referidos propósitos. Así lo expresa, a continuación de sus palabras en último lugar citadas:

Y para ello -dice- hay que empezar por convencer a los españoles de la sublime utilidad de la ciencia inútil.

Quedan expuestos los medios de enseñanza y aprendizaje que debieran establecerse en la Facultad de Ciencias. Pero ¿consideraba Menéndez Pelayo los mismos medios igualmente válidos para las facultades humanísticas? Sin temor a equivocarnos se puede responder que sí, ya que así se desprende de lo expresado por el propio polígrafo en el prólogo al manual de Literatura Española de F. M. Kelly (I90I). En él se manifiesta enemigo de compendios y manuales, como medios para llegar al conocimiento recto y adecuado de las cosas. Y, en este sentido, escribe:

Sólo la investigación propia y directa puede conducir a este fin (el mencionado conocimiento), tanto en las ciencias históricas como en todas las demás que tienen por base la observación y la experiencia. Con ser tan elemental esta verdad, conviene inculcarla en la mente de nuestros estudiosos, puesto que en España, más que en ninguna parte, se abusa de los fáciles medios de enseñanza que, simulando el conocimiento real, llegan a producir una ilusión doblemente funesta, y aun suelen incapacitar al sujeto para toda labor formal y metódica ${ }^{26}$.

Precisamente, juzga Menéndez Pelayo que la postración de nuestra enseñanza se debe, más que a ninguna otra causa, al continuo empleo de modelos repetitivos: libros de texto y apuntes de clase. Sin embargo, admite que los compendios, cuando están bien hechos, tienen algunos tipos de utilidad:

${ }_{25}$ Menéndez Pelayo, M. (1894) Esplendor y decadencia de la cultura científica española, en ibidem, p. 437s.

${ }_{26}$ MenÉndez Pelayo, M. (194I) Estudios de Crítica Histórica y Literaria. Madrid: Csic, I, p. 77 s. 
- Sirven para recordar lo sabido sistemáticamente ordenado.

- Si no pueden ni deben sustituir a las monografías, los manuales sí pueden dar su justo valor a los resultados de ellas en el conjunto del saber científico.

- Mediante la manifestación de las fuentes, sirven también, los manuales o compendios, para evitar lecturas inútiles o pesquisas ya hechas.

Para el estudiante universitario, quería, pues, D. Marcelino, trabajo de investigación personal en estrecho contacto con los maestros, y no métodos repetitivos y memorísticos. Se adelanta así, en muchos años, a alguno de los pioneros de la educación actual. Basta, para comprobarlo, recordar los principios de la educación personalizada y los puntos básicos del aprendizaje formulados por Rogers, el cual dice, en la misma línea que el sabio santanderino:

... no podemos enseñarle a otra persona directamente; sólo podemos facilitar su aprendizaje $\mathrm{e}^{27}$.

Y, en otro lugar, el propio Rogers se expresa del siguiente modo, al referirse a una educación no basada en la investigación y esfuerzo propios, sino en los ajenos:

Si tomamos las concepciones de los demás como nuestras, perdemos contacto con la sabiduría potencial de nuestro propio funcionamiento y perdemos confianza en nosotros mismos... Esta discrepancia fundamental entre los conceptos del individuo y sus experiencias reales... forman parte de la alienación fundamental del hombre moderno con respecto a sí mismo ${ }^{28}$.

Expuesto lo anterior, puede uno preguntarse: ¿ es actualmente posible una Universidad como la diseñada por D. Marcelino?; ¿cuál habría de ser el número de alumnos por profesor, para que la institución universitaria funcionase como él quería?; ¿cuántos recursos deberían ponerse a disposición de una tal Universidad? Resulta imposible responder aquí a esos interrogantes: queden simplemente formulados.

\subsubsection{El profesorado}

Nos queda referirnos al profesorado, tal como el gran polígrafo lo concebía. Y he aquí las preguntas cuyas respuestas es obligado indagar: ¿qué cualidades debería tener todo profesor?; ¿cómo debería ser seleccionado?; ¿cuál sería su formación?

Es evidente que esos interrogantes sólo pueden ser respondidos en función de las tareas que, según Menéndez Pelayo, el profesor debiera desempeñar. Tareas ésas que se deducen, en buena medida, de su ya expuesta manera de concebir la vida universitaria: comprobar la vocación de los alumnos para el estudio, seleccionarlos en función de dicha vocación y orientar y dirigir la formación pertinente, una vez incorporados a los estudios universitarios. De acuerdo con esto, se lee en el susodicho Dictamen... elaborado, repitámoslo, con el concurso de Salmerón:

27 Rogers, C. (1972) Psicoterapia centrada en el cliente. Buenos Aires: Paidós, p. 333.

${ }_{28}$ Rogers, C. (1975) Libertad y creatividad en la educación. Buenos Aires: Paidós, p. 185. 
Al profesor individualmente, y colectivamente a toda la facultad, incumbe el derecho de exigir del alumno todas las condiciones y pruebas que se crean necesarias para legitimar su vocación y los progresos que en la ciencia haga ${ }^{29}$.

Según lo dicho con anterioridad, D. Marcelino no admitía pruebas basadas en la pura memoria repetitiva: por tanto, a las que se refiere en este último texto habían de ser de otro tipo. Y, consecuentemente, el mismo Dictamen... carga sobre los profesores y las Facultades la responsabilidad «de no haber atajado a tiempo las vocaciones falsas» y la de no haber orientado adecuadamente el talento de los alumnos.

Pero ¿qué cualidades o aptitudes deberían tener los profesores, para cumplir dichas funciones o cometidos? El gran polígrafo no las expone directamente; pero sí indirecta, al hacer la crítica de algún pseudodocente por él sufrido, al que tacha de dogmático, intolerante, enrevesado y oscuro, incompetente y arbitrario... Es obvio que las cualidades contrarias a estos calificativos son las que debiera tener el profesor dotado de competencia.

Hemos dicho que otro asunto de gran importancia es el de la selección del profesorado. ¿Cuál era, al respecto, la opinión de D. Marcelino? Pensaba que el profesor debía irse formando día a día, desde que ponía sus pies como alumno en la Facultad, con tal de que estuviera dotado con aptitudes y vocación para el estudio, la investigación y la docencia. Y ésta sería la auténtica selección, y no la tantas veces equívoca de las oposiciones. Sin embargo, cree que éstas deben mantenerse hasta que se establezca el sistema propugnado, con objeto de evitar posibles arbitrariedades por parte de la Administración. Las siguientes son sus palabras:

... el sistema tantas veces aleatorio de la oposición que desaparecerá por sí mismo cuando el discípulo, día por día, se vaya transformando en maestro, pero que ahora conviene que subsista, porque todavía es el único dique contra la arbitrariedad burocrática ${ }^{30}$.

Parecidos juicios sobre las oposiciones serían posteriormente emitidos por Marañón y Ortega.

$$
* * *
$$

Hasta aquí, parte de lo que sobre educación, cultura y universidad expresó el inagotable D. Marcelino. Por esto, quizá, para terminar, nada mejor que traer a colación las palabras de dos autores, uno ya desaparecido, D. Dámaso Alonso, y otro, la profesora D. ${ }^{a}$ Carmen Iglesias, felizmente viva y recientemente nombrada directora de la Real Academia de la Historia.

Éstas son las palabras de D. Dámaso Alonso, según cita de Lázaro Carreter:

Muchas veces me siento abrumado por la mole de la obra de don Marcelino. Cuando me represento su grandeza, siento a algunas horas desánimo. ¿Merece la pena nuestro esfuerzo, hormiguitas que arrastramos nuestro grano de arena junto a la obra de la inmensa catedral que levantó un solo hombre?

29 Menéndez Pelayo, M. y Salmerón, N. (1896) Dictamen sobre... Madrid: Bbmp, i919, p. 59 s.

30 Menéndez Pelayo, M. (1894) Esplendor y decadencia de la cultura científica española, en (1953) La CE. Madrid: csic, p. 438. 
Pero no; esta es una idea pesimista e inmoral. Dios nos ha puesto ese portento: la obra de don Marcelino..., para que tengamos a la mano un modelo que imitar y a la par un refreno de la soberbia ${ }^{31}$.

Y las siguientes, las de la profesora Iglesias, referidas al conocimiento de autores de todo tipo -filósofos, teólogos, poetas...-, pertenecientes al siglo xviII:

... - -sin la asombrosa y sobresaliente erudición de Menéndez Pelayo que los sacó a la luz, uno a uno- seguirían seguramente sepultados en los legajos de los archivos y en las copias impresas de fondos de biblioteca que casi nadie tocaría. O lo que es peor, que ni siquiera, en algunos casos, se sospecharía de su existencia intelectual ${ }^{32}$.

\section{Conclusiones}

I. $^{\text {a) }}$ Menéndez Pelayo reconocía la decadencia educativa, cultural y científica de España.

2. $\left.{ }^{a}\right)$ La causa de esa decadencia la concretaba en el olvido de lo valioso de nuestro pasado histórico.

$\left.3 .^{a}\right)$ Consideraba necesario conocer nuestra historia, para eliminar, de cara al futuro, lo negativo de ella y tomar lo positivo como punto de arranque para seguir avanzando.

$\left.4 \cdot^{a}\right)$ El remedio de la calamitosa situación española lo ponía en la Universidad reformada-admisión y estancia en ella de los alumnos, correcta selección del profesorado, adecuado presupuesto...-.

$5^{\text {a })}$ Defendía el estudio de las lenguas clásicas: el latín, por su utilidad para conocer bien nuestro idioma; y el griego, para conocer la nomenclatura científica.

6. $\left.{ }^{a}\right)$ Propugnaba para el progreso material de España, la implantación de Facultades científico-técnicas iguales a las de los países más avanzados: Alemania, Inglaterra...

\section{Bibliografía}

Además de la consignada a lo largo del trabajo, han sido consultadas, entre otras, las siguientes obras:

Alonso de los Ríos, César; Duque, Aquilino y Gracia Noriega, Ignacio (20I2) Menéndez Pelayo: genio y figura. Madrid: Ediciones Encuentro.

Bonilla y Sanmartín, Adolfo (I9I4) Marcelino Menéndez y Pelayo. Madrid. Boletín de la Real Academia de la Historia.

CAcho Viu, Vicente (2010) La Institución Libre de Enseñanza. Madrid: Reedición de la Fundación Albéniz y de la Sociedad Estatal de Conmemoraciones Culturales. La primera edición es de 1962.

Menéndez Pelayo, Enrique y Menéndez Pelayo, Marcelino (1954) Epistolario. Madrid: Consejo Superior de Investigaciones Científicas.

Menéndez Pelayo, Marcelino (I99i) Epistolario. Edición de M. Revuelta Sañudo. MadridSantander: Fundación Universitaria Española, volumen 22.

Menéndez Pidal, Ramón (1971 $\left.{ }^{2}\right)$ Los españoles en la historia. Madrid: Espasa-Calpe.

${ }^{31}$ Lázaro Carreter, Fernando (1962²) Menéndez Pelayo: su época y su obra literaria. Salamanca: Anaya, I, p. II8.

${ }^{32}$ Iglesias, Carmen (2008) No siempre lo peor es cierto -Estudios sobre Historia de España-. Barcelona: Galaxia-Gutenberg, p. 504. 